\title{
Utilisation of Field Emission Scanning Electron Microscopy to Characterise an Active Brazing Alloy (ABA) Produced by an Electroless Plating Technique.
}

\author{
M. Brochu*, D. Knuutila*, M.D. Pugh**, R. Gauvin* and R.A.L. Drew* \\ * Department of Metals and Materials Engineering, McGill University, Montreal, Canada, H3A 2B2 \\ ** Department of Mechanical Engineering, Concordia University, Montreal, Canada, H3G 1M8
}

Brazing of ceramic materials requires the use of a filler metal containing an active element, such as titanium [1]. A new process for production of exotic ABA was developed using an electroless deposition technique. Copper was deposited at the surface of dense and porous titanium powder (-325 mesh). Copper deposition was performed in a copper sulphate solution $\left(\mathrm{CuSO}_{4}\right)$ with various additives for bath stabilisation [2]. The plating temperature was maintained to $70^{\circ} \mathrm{C}$. The $\mathrm{pH}$ was varied between 12.5 and 13 and plating time was varied between 5 to 60 minutes. The deposition reaction involves precipitation of copper atoms from the following reaction:

$$
\mathrm{Cu}^{2+}+2 \mathrm{HCHO}+4 \mathrm{OH}^{-} \Rightarrow \mathrm{Cu}^{0}+\mathrm{H}_{2}+2 \mathrm{H}_{2} \mathrm{O}+2 \mathrm{HCO}_{2}^{-}
$$

High resolution microscopy was used to characterize the copper precipitate size and morphology as a function of powder type and $\mathrm{pH}$ of the deposition bath. The analysis were performed on a Hitachi FESEM S4700 at 3kV, with working distance of $6 \mathrm{~mm}$ or less on secondary electron mode with the upper detector.

Figure 1 presents a backscattered image of a cross section of a coated titanium particle. The copper deposit is homogeneous and possesses an average thickness of 5 microns ( $\approx 20$ coatings). It can also be observed that copper precipitates into the cavities of the powder. A main advantage of using the electroless plating technique over electrolytic is the possibility of deposition over the entire surface. Figure 2 presents a Ti-sponge particle after a deposition time of 10 minutes and Figure 3 shows the copper deposit in these pores. With this copper deposition into the pores, the final coated powder will have a higher copper content with smaller particle size.

Figures 3 and 4 show high magnification image of the deposit at a plating $\mathrm{pH}$ of 13 and 12.5 respectively. For lower pH (Fig. 4), the nano-sites of the copper precipitates possess a rounded shape. Higher $\mathrm{pH}$ plating produces a faceted-type (rosette) of deposit. Other nucleation sites can be observed on the particle surface between the copper rosettes, which indicates good surface deposition.

Figure 5 presents an example of agglomeration of the coated particles. The agglomeration is strongly influenced by the morphology of the deposit. The final particle agglomerate size of the powder plated at $\mathrm{pH} 13$ was larger. Encroachment between adjacent faceted copper deposits is believed to be responsible for this higher rate of agglomeration.

In conclusion, high resolution FESEM was successfully used to characterize the morphology and quality of the copper deposit in order to optimise the electroless plating parameters during powder coating. The utilisation of the upper detector allows imaging inside cavities, which was not possible using conventional secondary electron detector. The ABA produced, gave excellent properties during ceramic-metal joining. 
References:

1. M.G. Nicholas, Joining Process; Introduction to brazing and diffusion bonding, Kluwer Academic Publishers, 1998, 333p.

2. ASM Handbook, Volume 5; Surface Engineering, ASM International, 1994.

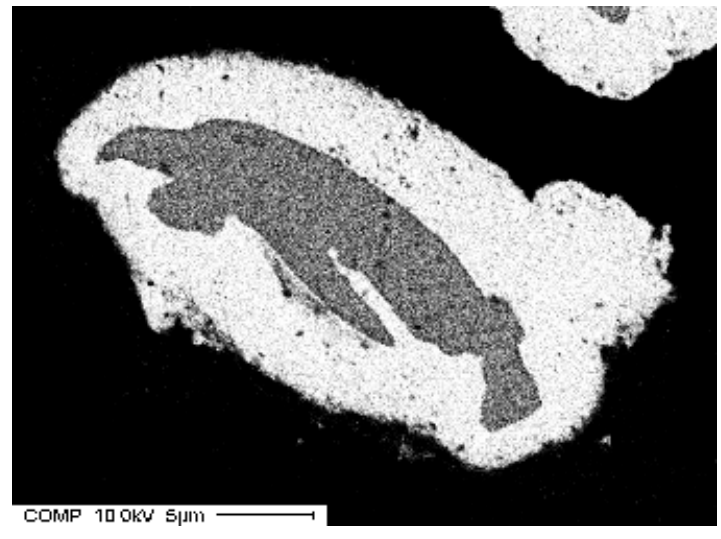

Figure 1 - Cross section of titanium powder coated with copper.



Figure 3 - Faceted nature of copper deposit in the pore shown in Figure 2.



Figure 5 - Particle agglomeration after multiple plating process.

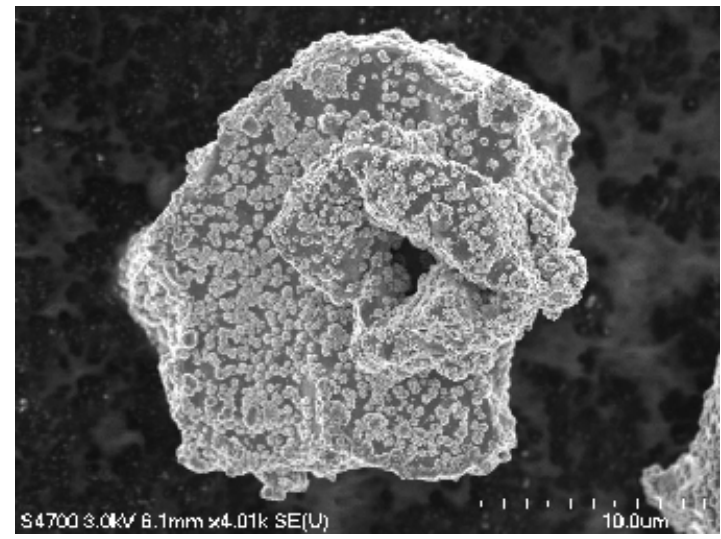

Figure 2 - Sponge titanium particle after 10 minutes of plating at $\mathrm{pH} 13$.

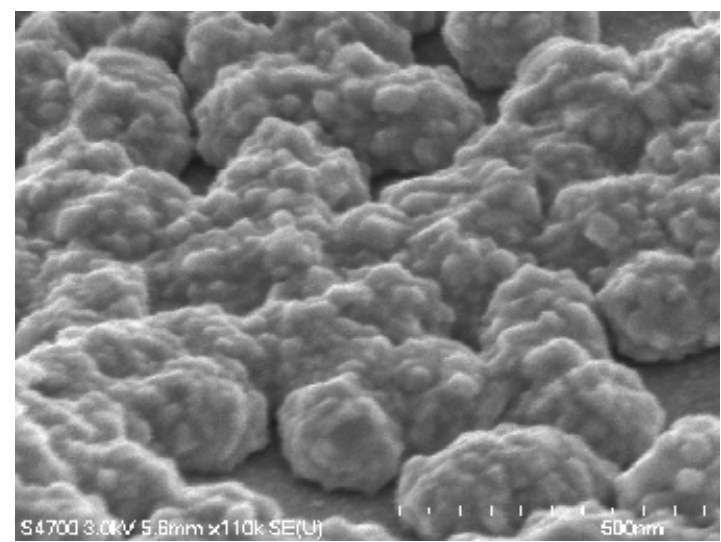

Figure 4 - Rounded nano-sites of copper deposited at $\mathrm{pH} 12.5$. 